\title{
Treatment Outcomes of Hepatitis C-Infected Patients in Specialty Clinic vs. Primary Care Physician Clinic: A Comparative Analysis
}

\author{
Taseen Ahmed Syed (D, ${ }^{1,2}$ Muhammad Hassaan Bashir, ${ }^{3}$ Samid Muhammad Farooqui (D), \\ Allshine Chen, ${ }^{4}$ Sixia Chen, ${ }^{4}$ Salman Nusrat $\mathbb{D}^{\mathbb{D}},{ }^{5,6,7}$ and Javid Fazili ${ }^{6,7}$ \\ ${ }^{1}$ Department of Internal Medicine, University of Oklahoma Health Sciences Center, 1100 N Lindsay Ave, Oklahoma City, \\ OK 73104, USA \\ ${ }^{2}$ Department of Gastroenterology, Virginia Commonwealth University, Richmond, VA, USA \\ ${ }^{3}$ Department of Gastroenterology, SUNY Health Science Center, Brooklyn, New York, USA \\ ${ }^{4}$ Department of Biostatistics \& Epidemiology, University of Oklahoma Health Sciences Center, 801 NE 13th St., Oklahoma City, \\ OK, USA \\ ${ }^{5}$ Department of Medicine, Neurogastroenterology and Motility Program, University of Oklahoma Health Sciences Center, \\ Oklahoma City, OK, USA \\ ${ }^{6}$ Department of Medicine, Section of Digestive Diseases and Nutrition, University of Oklahoma Health Sciences Center, \\ Oklahoma City, OK, USA \\ ${ }^{7}$ Department of Medicine, Section of Digestive Diseases and Nutrition, Veterans Affairs Medical Center, Oklahoma City, OK, USA
}

Correspondence should be addressed to Taseen Ahmed Syed; syedtaseenahmed@hotmail.com

Received 29 December 2018; Revised 24 March 2019; Accepted 16 April 2019; Published 4 June 2019

Academic Editor: Haruhiko Sugimura

Copyright (C) 2019 Taseen Ahmed Syed et al. This is an open access article distributed under the Creative Commons Attribution License, which permits unrestricted use, distribution, and reproduction in any medium, provided the original work is properly cited.

\begin{abstract}
Background. Oral direct-acting antivirals (DAAs) provide an exceptional opportunity to treat hepatitis C virus (HCV) infection. Goals. We compared the treatment outcomes between specialty and primary care physician (PCP) clinics for patients treated with DAAs. Methods. We performed a retrospective analysis of patients treated for HCV in our PCP clinics and specialty; liver and gastroenterology clinics and gastroenterology clinics. We used the two-sided $t$-test and the chi-square test to compare the means of continuous and categorical variables, respectively. Results. Data from a total of 377 patients was analyzed (PCP clinic: $n=185$ and specialty clinic: $n=192$ ). There was no significant difference between age, race, and gender. Model for End-Stage Liver Disease (MELD) and Child-Turcotte-Pugh (CTP) scores were comparable at baseline. Greater than $90 \%$ of the patients achieved sustained virological response (SVR) with no difference between the groups. Conclusions. Uncomplicated patients can be treated for hepatitis C by their PCPs with DAAs with similar treatment outcomes to specialty clinics. There should be explicit guidelines on patient eligibility for treatment by PCPs vs. specialists.
\end{abstract}

\section{Introduction}

Novel oral direct-acting antivirals (DAAs) have completely changed the spectrum of hepatitis $C$ treatment with multiple studies showing sustained virological response (SVR) of over $90 \%$ for many genotypes [1-3]. Approximately 3.5 million people in the USA are infected with HCV [4]. Since the introduction of DAAs in the late 2013, almost 350,000 patients in the USA have been treated with these agents. This is a small portion of the HCV-infected population which leaves a huge number of treatment-naïve patients who can benefit from this cost-effective treatment $[5,6]$. The outpatient setting has always focused on screening, diagnosis, and referring patients for appropriate treatment through specialists including gastroenterologists and hepatologists $[7,8]$. There has always been some amount of uneasiness among primary care physicians (general internal medicine and family medicine) [9] for the management of important aspects of HCVrelated healthcare [10-12]. Over the last few years, trends have changed from a merely screening-and-referral strategy 
to a more self-initiated treatment of $\mathrm{HCV}$ infection by primary care physicians (PCPs) themselves [13]. One reason for this shifting paradigm was Project ECHO (Extension for Community Healthcare Outcomes), which was launched in 2003 in Mexico and amplified the capacity to practice the best medicine in underdeveloped and rural areas through telemedicine including video conferencing. The purpose of this was to enhance capabilities of PCPs for complex patient care in underserved communities [14]. A subsequent study published by Arora et al. in New England Journal of Medicine in 2011 showed that the quality of hepatitis $\mathrm{C}$ treatment received by physicians trained through the program $\mathrm{ECHO}$ was comparable to specialist's level care [15]. This ECHO act was approved by the US in the late 2016. A similar study recently published in April 2017 used the project ECHO to the VA population (VA-ECHO) [16]. The results were promising and showed that telemedicine through Project ECHO can increase awareness about hepatitis $\mathrm{C}$ treatment initiation especially in Veterans Affairs (VA) hospitals in far rural areas. The ECHO project is cost-effective and stresses the fact that chronic HCV infection burden in the US can be reduced by increasing awareness of hepatitis $\mathrm{C}$ treatment in the primary care setting [17-19]. The successful implementation of this project in multiple states has proven the utility of PCPs to treat HCV infection through expanding their educational capacity and increasing their comfortability level $[15,20]$. The purpose of our study was to assess outcomes of PCPs treating $\mathrm{HCV}$-infected US veterans with DAAs after the incorporation of educational initiatives and collaborations with specialists.

\section{Methods}

We performed a retrospective chart review to identify patients treated for HCV from January 2014 to May 2017, at our PCP clinics and specialty; liver and gastroenterology clinics. The departments of internal medicine, gastroenterology, hepatology, and pharmacy got together to establish a multidisciplinary approach to deal with the shortage of physicians available to treat hepatitis $C$ patients in the DAA era as many of them who were not considered for treatment in the interferon era were now eligible for treatment with DAAs. We had two educational sessions conducted by hepatologists for PCPs on chronic HCV management with DAAs. Afterwards, the PCPs had full support of the pharmacy department in monitoring and dispensing of these medications.

After this intervention and from May 2016 onwards, it was decided to send noncirrhotics to PCP clinics for treatment whereas the specialty clinic was still treating both cirrhotics and noncirrhotics in addition to patients who had coinfection with hepatitis B virus (HBV) and $\mathrm{HCV}$, were human immunodeficiency virus (HIV) infected, had ribavirin in the treatment regimen, or had prior treatment failure.

2.1. Study Population. A total number of $731 \mathrm{HCV}$-infected patients were treated by 62 primary care and 5 specialty physicians at our Veterans Affairs Medical Center. Clinical outcomes of patients treated in the PCP clinic were compared to patients treated in the specialty clinic. We collected the baseline characteristics (age, gender, race, smoking history, alcohol history, and HCV genotype), baseline HCV RNA level, achievement of SVR, coinfection with hepatitis B or $\mathrm{HIV}$, hepatocellular carcinoma (HCC) development after starting treatment, Model of End Stage Liver Disease (MELD) scores, Child-Turcotte-Pugh (CTP) scores, and other cirrhosis-related pre- and posttreatment laboratory parameters.

2.2. Inclusion Criteria. Adults, both men and women, between ages 18-79 years, were included in the study. These patients were infected with $\mathrm{HCV}$ and received treatment in their PCP or specialty clinic.

2.3. Exclusion Criteria. Patients with loss to follow-up due to transfer of care to another facility, death before SVR, or no show for SVR labs were not included as per protocol.

2.4. Statistical Analysis. We used the two-sided $t$-test and the chi-square test to compare the means of continuous and categorical variables, respectively. The analysis was performed with the statistical analysis software (SAS). A $p$ value of $<0.05$ was considered statistically significant. The $95 \%$ confidence interval was calculated using a Wald asymptotic 95\% confidence interval for difference of two proportions.

2.5. Main Outcome Measure. The primary endpoint was SVR (an undetectable HCV viral load 12-week posttreatment), which represents cure. Development of HCC was our secondary endpoint.

\section{Results}

In total, the data from $673 \mathrm{HCV}$-infected patients was extracted. 488 patients were treated in the specialty clinic and 185 in the PCP clinic (Figure 1). The rate of SVR was high in the PCP clinic as compared to specialty clinic (93.51 vs. 92.40, $p=0.62$ ). Since cirrhotics were being treated in the specialty clinic, they were excluded to prevent any bias, since cirrhosis is an independent risk factor for poor treatment outcomes (decreased SVR rates) [21]. Data from a total of 377 patients was reanalyzed. 192 and 185 noncirrhotics (via biochemical and radiological studies) were treated in the specialty and PCP clinics, respectively. Compliance to medication was noted by regular visits at the time of enrollment, four weeks into treatment (4VR), end of treatment (ETR), and SVR lab withdrawal. Demographic variables are presented in Table 1, and clinical outcomes assessed by the chi-square or $t$-test are presented in Table 2. The groups were comparable in regard to race, gender, MELD, CTP, FIB-4 scores, and posttreatment labs (AST, ALT, hemoglobin, total bilirubin, albumin, and sodium) (Table 2). All patients in both groups completed therapy. The HCV genotype was known for all patients; 112 (58.33\%) specialty clinic and 113 (61.08\%) PCP clinic patients had genotype 1a, which was the most common genotype. SVR was achieved in more than $90 \%$ of the patients in both groups separately, and there was no statistical difference for SVR results between the groups (Table 2). The risk difference of the proportions of 


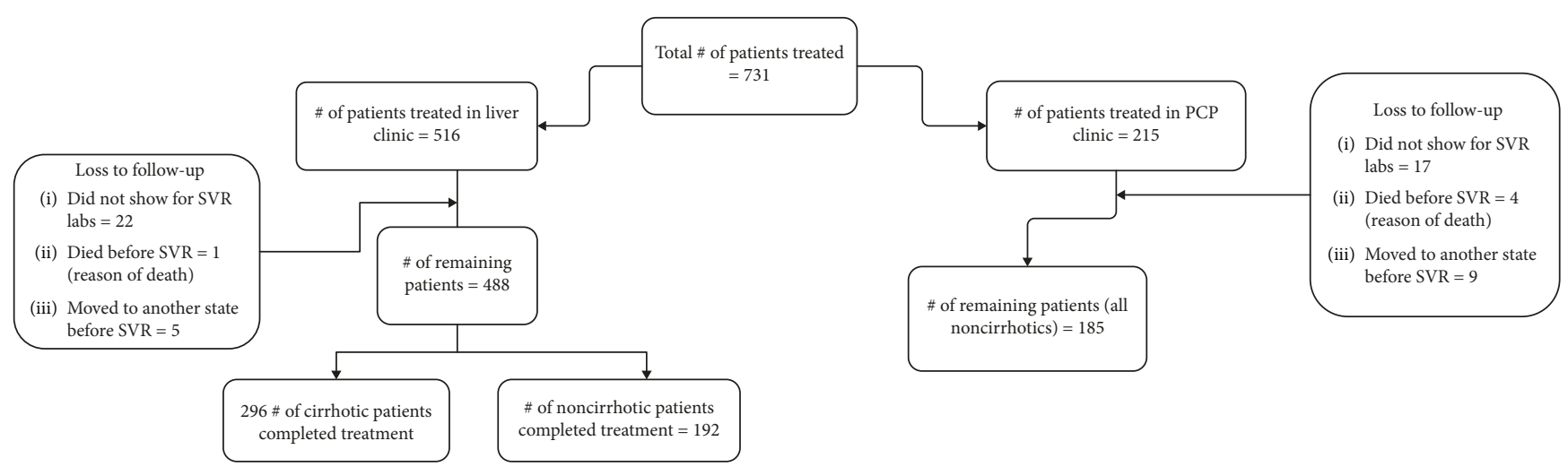

Figure 1: Flow chart.

TABle 1: Demographic values by clinic with the chi-square test or the $t$-test.

\begin{tabular}{|c|c|c|c|}
\hline Demographic variables & GI clinic $(n=192)$ & PCP clinic $(n=185)$ & $p$ value \\
\hline Age, average (range) & $60.71(29-78)$ & $61.54(30-87)$ & 0.27 \\
\hline Male sex, $n(\%)$ & $180(94.74 \%)$ & $182(98.38 \%)$ & 0.05 \\
\hline \multicolumn{4}{|l|}{ Race, $n(\%)$} \\
\hline (a) Caucasian & $130(73.00 \%)$ & $114(64.41 \%)$ & 0.22 \\
\hline (b) African American & $42(23.60 \%)$ & $55(31.07 \%)$ & \\
\hline (c) Other* & $6(3.37 \%)$ & $8(4.52 \%)$ & \\
\hline (d) Unknown & $14(7.29 \%)$ & $8(4.52 \%)$ & \\
\hline Cirrhosis, $n(\%)$ & $0(0.0 \%)$ & $0(0.0 \%)$ & \\
\hline \multicolumn{4}{|l|}{ Comorbidities } \\
\hline (a) CHF, $n(\%)$ & $5(2.63 \%)$ & $12(6.52 \%)$ & 0.07 \\
\hline (b) HTH, $n(\%)$ & $123(64.40 \%)$ & $123(66.85 \%)$ & 0.62 \\
\hline History of the previous alcohol use, $n(\%)$ & $178(94.68 \%)$ & $109(62.29 \%)$ & $<0.01$ \\
\hline History of the previous smoking, $n(\%)$ & $133(70.74 \%)$ & $48(29.09 \%)$ & $<0.01$ \\
\hline History of the previous IVDU, $n(\%)$ & $115(61.17 \%)$ & $46(27.38 \%)$ & $<0.01$ \\
\hline
\end{tabular}

${ }^{*}$ Other: Native American and Asian. Abbreviations: GI: gastroenterology; PCP: primary care physician; CHF: congestive heart failure; HTN: hypertension; IVDU: intravenous drug use.

patients achieving SVR in both groups (95.8\% in the GI clinic and $93.5 \%$ in the PCP clinic) was $2.32 \%$ with $95 \%$ CI of $-2.05 \%$ to $6.69 \%$. The number of treatment-naïve patients was higher in the PCP clinic as compared to GI clinic (92.97\% vs. $77.60 \%, p=<0.01$ ) (Table 3 ). The top three drugs used in the PCP clinic were Harvoni, Epclusa, and Zepatier whereas in the GI clinic, Harvoni, sofosbuvir/ribavirin, and Viekira/ribavirin were more often used. $97.56 \%$ and $93.06 \%$ of patients achieving SVR in the GI and PCP clinics, respectively, received Harvoni as sole treatment (Table 4). Most patients achieving SVR were genotype 1a in both groups (96.4\% in the GI clinic vs. $92.92 \%$ in the PCP clinic) (Table 5). MELD, CTP, and FIB-4 scores were comparable at SVR. No major complications such as death were reported. Only two patients developed HCC, one from each group. There was no difference in markers of disease severity posttherapy, assessed by MELD, CTP, and FIB-4 scores (Table 2). As far as high-risk behavior was concerned, history of smoking, alcohol intake, and IVDU was more common in patients treated in the GI clinic $(p<0.01)$.

\section{Discussion}

HCV infection has always been a prevalent but less diagnosed viral infection. The reason is the knowledge gap and lack of educational expertise outside of the specialist practice $[7,22]$. However, treatment of hepatitis $C$ by a PCP results in less loss to follow-up due to familiarity with patient social dynamics prior to HCV treatment initiation. Treating $\mathrm{HCV}$ infection themselves increases their awareness of liver diseases and is a source of intellectual satisfaction that can prevent burn out as well [23]. Contrary to this, PCPs have to face certain drawbacks. PCPs have to treat patients in entirety and thus put a knowledge burden on them. HCV treatment is often restricted by payers to patients with advanced fibrosis forcing PCPs to perform additional tests like a fibroscan that requires another complex level of understanding [24, 25]. Time restraints, knowledge gaps, easy access to the specialty referral, apprehension of medicolegal litigation, lack of HCV treatment in PCP quality measures, and provider restrictions on the prescription of independent 


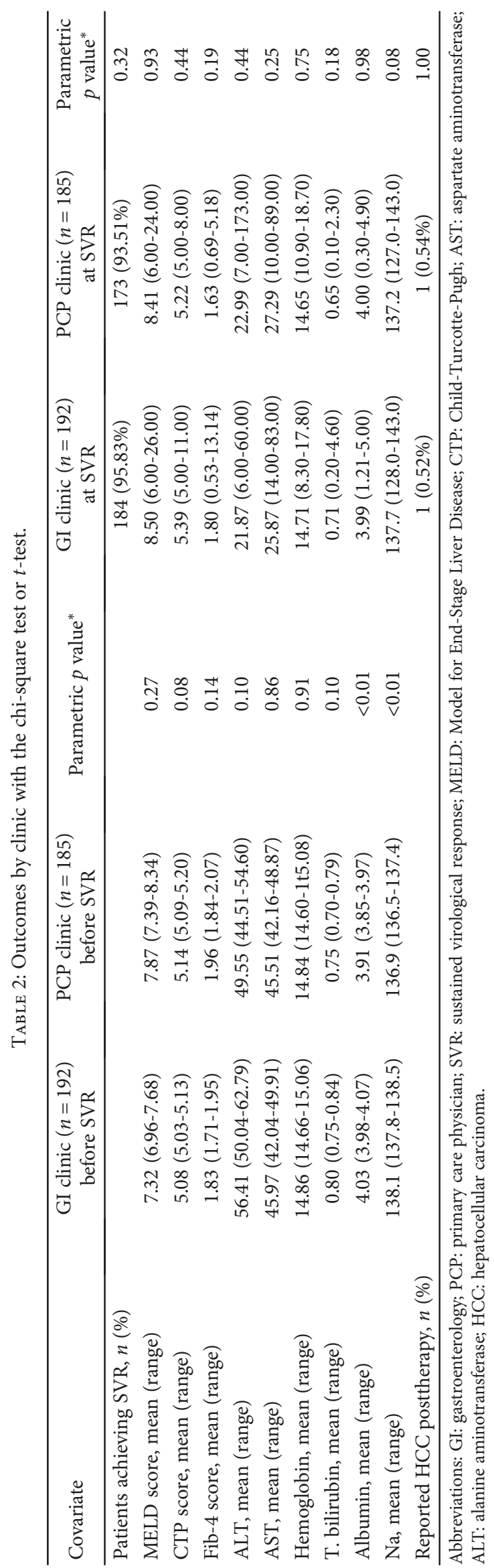


TABle 3: Prior hepatitis C treatment regimens for patients treated in GI vs. PCP clinic.

\begin{tabular}{|c|c|c|c|}
\hline Prior treatment & GI clinic (noncirrhotic) Group-1 $(n=192)$ & PCP clinic (noncirrhotic) Group-2 $(n=185)$ & $p$ value \\
\hline Treatment naïve, $n(\%)$ & $149(77.60)$ & $172(92.97)$ & $<0.01$ \\
\hline Previous treatment, $n(\%)$ & $43(22.40)$ & $13(7.03)$ & \\
\hline Interferon+ribavirin & $33(17.19)$ & $11(5.95)$ & $<0.01$ \\
\hline PEG/ribavirin/boceprevir & $5(2.60)$ & $1(0.54)$ & \\
\hline Harvoni \& ribavirin & $4(2.08)$ & 0 & \\
\hline Viekira Pak+ribavirin & 0 & $1(0.54)$ & \\
\hline Interferon & $1(0.52)$ & 0 & \\
\hline
\end{tabular}

Abbreviations: GI: gastroenterology; PCP: primary care physician; PEG: pegylated interferon alpha.

TABLE 4: SVR outcomes based on the prescribed anti-HCV medication.

\begin{tabular}{|c|c|c|c|c|c|}
\hline Current treatment & $\begin{array}{c}\text { GI clinic } \\
\text { (noncirrhotic) } \\
\text { Group-1 }(n=192)\end{array}$ & $\begin{array}{c}\text { PCP clinic } \\
\text { (noncirrhotic) } \\
\text { Group-2 }(n=185)\end{array}$ & $p$ value & $\begin{array}{c}n(\%) \text { of patients achieving } \\
\text { SVR in GI clinic for } \\
\text { the drug }\end{array}$ & $\begin{array}{c}n(\%) \text { of patients achieving } \\
\text { SVR in PCP clinic for } \\
\text { the drug }\end{array}$ \\
\hline Harvoni & $123(64.06)$ & $144(77.84)$ & $<0.01$ & $120(97.56)$ & $134(93.06)$ \\
\hline Sofosbuvir+ribavirin & $33(17.19)$ & 0 & & $32(96.97)$ & 0 \\
\hline Epclusa & 0 & $25(13.51)$ & & 0 & $24(96.00)$ \\
\hline Viekira+ribavirin & $17(8.85)$ & 0 & & $15(88.24)$ & 0 \\
\hline Zepatier & 0 & $15(8.11)$ & & 0 & $14(93.33)$ \\
\hline Harvoni+ribavirin & $9(4.69)$ & $1(0.54)$ & & $7(77.78)$ & $1(100)$ \\
\hline Sofosbuvir+Harvoni & $3(1.56)$ & 0 & & $3(100)$ & 0 \\
\hline Sofosbuvir+simeprevir & $1(0.52)$ & 0 & & $1(100)$ & 0 \\
\hline Daklinza+sofosbuvir & $1(0.52)$ & 0 & & $1(100)$ & 0 \\
\hline Sofosbuvir+ribavirin+IFN & $1(0.52)$ & 0 & & $1(100)$ & 0 \\
\hline Ledipasvir/sofosbuvir & $1(0.52)$ & 0 & & $1(100)$ & 0 \\
\hline Viekira & $1(0.52)$ & 0 & & $1(100)$ & 0 \\
\hline Technivie/ribavirin & $1(0.52)$ & 0 & & $1(100)$ & 0 \\
\hline Harvoni/Viekira/Zepatier & $1(0.52)$ & 0 & & $1(100)$ & 0 \\
\hline
\end{tabular}

Abbreviations: GI: gastroenterology; PCP: primary care physician; SVR: sustained virological response; IFN: interferon.

HCV treatment are some of the reasons why PCPs are not comfortable treating hepatitis C $[23,26,27]$. Definitely, voluntary participation by PCPs is still the key factor here.

There have been no guidelines on when HCV-infected patients should be referred to the PCP clinic. In our institution, we established our own referral criteria that focused on complex patients being treated in the specialty clinic. The updated guidelines are written by specialists for specialists and are not intended for the PCP audience. When it comes to referral to the specialty clinic, there are no clear indications when PCP should refer to specialists rather than treating themselves [28]. Our study found that HCVinfected patients with mild disease as assessed by MELD score, CTP score, and FIB-4 score can be treated successfully by PCPs with comparable SVR to the specialty clinics. As far as referral is concerned, guidelines based on firm evidence and extensive research with clear-cut indications on when to request a specialist referral should be outlined.

Finally, the elimination of hepatitis $\mathrm{C}$ is a public health goal and to achieve, it will require a multidisciplinary approach with hepatitis $\mathrm{C}$ treatment awareness and access to multiple health care workers in health care settings including PCP clinics, pharmacist clinics, methadone clinics, and prisons. In our clinics, pharmacists played a role of a clinical and specialty pharmacist and as such, assisted physicians in prior medication authorization, prescription fulfillment, and patient telephonic counseling. On the other hand, a health system specialty pharmacist can be directly involved in hepatitis $\mathrm{C}$ treatment initiation further reducing the burden of hepatitis $\mathrm{C}$ management that has shown promising results $[29,30]$. Since different DAAs are selected based on their pharmacodynamics, adverse effects, efficacy, cost implications, and insurance approval, the role of pharmacists can be promising to enhance treatment access. By the participation of PCPs and pharmacists, the WHO goals for viral hepatitis can be achieved.

4.1. Study Limitations. There are several limitations to this study. This study took place in different clinics (PCP vs. GI) but in one hospital setting. Thus, these findings may not be generalizable to all settings. We did not directly study the parameters for nonadherence rather considered SVR to 
TABLE 5: SVR outcomes based on the hepatitis C genotype.

\begin{tabular}{|c|c|c|c|c|c|}
\hline $\begin{array}{l}\text { Hepatitis C } \\
\text { genotype }\end{array}$ & $\begin{array}{l}\text { GI clinic (noncirrhotic) } \\
\text { Group-1 }(n=192)\end{array}$ & $\begin{array}{l}\text { PCP clinic (noncirrhotic) } \\
\text { Group-2 }(n=185)\end{array}$ & $p$ value & $\begin{array}{c}n(\%) \text { of patients achieving } \\
\text { SVR in GI clinic for } \\
\text { the genotype }\end{array}$ & $\begin{array}{c}n(\%) \text { of patients achieving } \\
\text { SVR in PCP clinic for } \\
\text { the genotype }\end{array}$ \\
\hline $1 \mathrm{a}, n(\%)$ & $112(58.33)$ & $113(61.08)$ & $<0.01$ & $108(96.43)$ & 105 (92.92) \\
\hline $1 b, n(\%)$ & $32(16.67)$ & $50(27.03)$ & & $31(96.88)$ & $47(94.00)$ \\
\hline $2 \mathrm{~b}, n(\%)$ & $25(13.02)$ & $12(6.49)$ & & $25(100)$ & $11(91.67)$ \\
\hline $2, n(\%)$ & $8(4.17)$ & $1(0.54)$ & & $8(100)$ & $1(100)$ \\
\hline $4, n(\%)$ & $4(2.08)$ & 0 & & $4(100)$ & 0 \\
\hline $3 \mathrm{a}, n(\%)$ & $3(1.56)$ & $3(1.62)$ & & $2(66.67)$ & $3(100)$ \\
\hline $1, n(\%)$ & $3(1.56)$ & 0 & & $2(66.67)$ & 0 \\
\hline $2 \mathrm{a} / 2 \mathrm{c}, n(\%)$ & $2(1.04)$ & $2(1.08)$ & & $2(100)$ & $2(100)$ \\
\hline $3, n(\%)$ & $2(1.04)$ & 0 & & $1(50.00)$ & 0 \\
\hline 1a/1b, $n(\%)$ & $1(0.52)$ & $2(1.08)$ & & $1(100)$ & $2(100)$ \\
\hline $2 \mathrm{~b} \& 3, n(\%)$ & 0 & $1(0.54)$ & & 0 & $1(100)$ \\
\hline $4 \mathrm{a} / 4 \mathrm{c} / 4 \mathrm{~d}, n(\%)$ & 0 & $1(0.54)$ & & 0 & $1(100)$ \\
\hline
\end{tabular}

Abbreviations: GI: gastroenterology; PCP: primary care physician; SVR: sustained virological response.

be a marker of adherence to the treatment regimen. As compared to PCP clinics, the specialty clinics treated more complicated patients with past high-risk lifestyle habits including smoking, alcohol intake, and intravenous drug use. These lifestyle differences might be a potential cause of confounding.

\section{Conclusions}

HCV patients with mild disease severity who were treated in the PCP clinics achieved SVR at rates comparable to HCV patients treated in the specialty clinics. This high SVR was achieved through a multidisciplinary approach including PCPs. Uncomplicated patients can be treated for hepatitis C by their PCPs with safe and cost-effective DAAs and thereby relieve the heavy burden on the specialty clinics especially in Veterans Affairs (VA) Health which is considered to be the world's largest hepatitis C care provider. However, further educational initiatives and explicit practice guidelines for PCPs are needed.

\section{Data Availability}

Not applicable. We do not have publicly achieved datasets.

\section{Disclosure}

The preliminary results of this research work have been presented as a research poster in DDW18. The role of the funder was approval of the manuscript and decision to submit the manuscript for publication. The funder had no role in the design and conduct of the study; collection, management, analysis, and interpretation of the data; and preparation or review of the manuscript.

\section{Conflicts of Interest}

The authors declare that they have no conflicts of interest.

\section{Authors' Contributions}

J. Fazili was the principal investigator who conceived, supervised, reviewed, and approved the final manuscript and has control of the decision to publish with the final approval of the manuscript; M. Bashir, T.A. Syed, and S. Farooqui were involved in study design, data retrieval, manuscript drafting, and final approval of the manuscript; S. Chen and A. Chen were involved in the data acquisition, statistical analysis, and final approval of the manuscript; S. Nusrat was involved in study design, statistical revisions, critical revision, and final approval of the manuscript.

\section{Acknowledgments}

Partial funding was provided by National Institutes of Health, National Institute of General Medical Sciences (grant 2U54GM104938-06).

\section{References}

[1] M. Reig, Z. Mariño, C. Perelló et al., "Unexpected high rate of early tumor recurrence in patients with HCV-related HCC undergoing interferon-free therapy," Journal of Hepatology, vol. 65, no. 4, pp. 719-726, 2016.

[2] M. S. Sulkowski, H. E. Vargas, A. M. di Bisceglie et al., "Effectiveness of simeprevir plus sofosbuvir, with or without ribavirin, in real-world patients with HCV genotype 1 infection," Gastroenterology, vol. 150, no. 2, pp. 419-429, 2016.

[3] A. I. Aspinall, A. A. Shaheen, G. S. Kochaksaraei et al., "Realworld treatment of hepatitis $\mathrm{C}$ with second-generation direct-acting antivirals: initial results from a multicentre Canadian retrospective cohort of diverse patients," CMAJ Open, vol. 6, no. 1, pp. E12-E18, 2018.

[4] B. R. Edlin, B. J. Eckhardt, M. A. Shu, S. D. Holmberg, and T. Swan, "Toward a more accurate estimate of the prevalence of hepatitis C in the United States," Hepatology, vol. 62, no. 5, pp. 1353-1363, 2015. 
[5] G. J. Buckley and B. L. Strom, Eds., Eliminating the Public Health Problem of Hepatitis B and C in the United States: Phase One Report, The National Academic Press, Washington, DC, 2016.

[6] M. Najafzadeh, K. Andersson, W. H. Shrank et al., "Costeffectiveness of novel regimens for the treatment of hepatitis C virus," Annals of Internal Medicine, vol. 162, no. 6, pp. 407-419, 2015.

[7] E. Lebovics, R. Torres, and L. K. Porter, "Primary care perspectives on hepatitis $\mathrm{C}$ virus screening, diagnosis and linking patients to appropriate care," The American Journal of Medicine, vol. 130, no. 2, pp. S1-S2, 2017.

[8] A. A. Artenie, J. Bruneau, A. Levesque, and J.-M. B. Wansuanganyi, "Role of primary care providers in hepatitis $\mathrm{C}$ prevention and care: one step away from evidence-based practice," Canadian Family Physician, vol. 60, no. 10, pp. 881-882, 2014.

[9] E. C. Clark, B. P. Yawn, J. M. Galliher, J. L. Temte, and J. Hickner, "Hepatitis C identification and management by family physicians," Family Medicine, vol. 37, no. 9, pp. 644-649, 2005.

[10] R. Cozzolongo, R. Cuppone, J. Petruzzi, T. Stroffolini, and O. G. Manghisi, "Approach of primary care physicians to hepatitis C: an educational survey from a Southern Italian area," The Journal of Infection, vol. 51, no. 5, pp. 396-400, 2005.

[11] T. M. Shehab, M. Orrego, R. Chunduri, and A. S. F. Lok, "Identification and management of hepatitis $C$ patients in primary care clinics," The American Journal of Gastroenterology, vol. 98, no. 3, pp. 639-644, 2003.

[12] T. M. Shehab, S. S. Sonnad, and A. S. F. Lok, "Management of hepatitis $C$ patients by primary care physicians in the USA: results of a national survey," Journal of Viral Hepatitis, vol. 8, no. 5, pp. 377-383, 2001.

[13] N. Gilani, H. Rodriguez-Luna, M. F. Hanif et al., "Effectiveness of multidisciplinary approach in patients undergoing therapy for chronic hepatitis C," The Journal of the Pakistan Medical Association, vol. 67, no. 10, pp. 1487-1492, 2017.

[14] K. Khatri, M. Haddad, and D. Anderson, "Project ECHO: replicating a novel model to enhance access to hepatitis $\mathrm{C}$ care in a community health center," Journal of Health Care for the Poor and Underserved, vol. 24, no. 2, pp. 850-858, 2013.

[15] S. Arora, K. Thornton, G. Murata et al., "Outcomes of treatment for hepatitis $\mathrm{C}$ virus infection by primary care providers," The New England Journal of Medicine, vol. 364, no. 23, pp. 2199-2207, 2011.

[16] L. A. Beste, T. J. Glorioso, P. M. Ho et al., "Telemedicine specialty support promotes hepatitis $\mathrm{C}$ treatment by primary care providers in the Department of Veterans Affairs," The American Journal of Medicine, vol. 130, no. 4, pp. 432-438.e3, 2017.

[17] T. Rattay, I. P. Dumont, H. S. Heinzow, and D. W. Hutton, "Cost-effectiveness of access expansion to treatment of hepatitis C virus infection through primary care providers," Gastroenterology, vol. 153, no. 6, pp. 1531-1543.e2, 2017.

[18] V. Tahan, A. Almashhrawi, R. Mutrux, and J. A Ibdah, "Show Me ECHO-Hepatitis C: a telemedicine mentoring program for patients with hepatitis $\mathrm{C}$ in underserved and rural areas in Missouri as a model in developing countries," The Turkish Journal of Gastroenterology, vol. 26, no. 6, pp. 447-449, 2015.
[19] J. Grebely and G. J. Dore, “An expanding role for primary care providers in the treatment of hepatitis $C$ virus infection in the community," Hepatology, vol. 54, no. 6, pp. 2258-2260, 2011.

[20] K. Mitruka, K. Thornton, S. Cusick et al., "Expanding primary care capacity to treat hepatitis $\mathrm{C}$ virus infection through an evidence-based care model - Arizona and Utah, 20122014," Morbidity and Mortality Weekly Report, vol. 63, no. 18, pp. 393-398, 2014.

[21] A. Sangiovanni, G. M. Prati, P. Fasani et al., "The natural history of compensated cirrhosis due to hepatitis C virus: a 17-year cohort study of 214 patients," Hepatology, vol. 43, no. 6, pp. 1303-1310, 2006.

[22] Z. M. Younossi, M. E. Singer, H. M. Mir, L. Henry, and S. Hunt, "Impact of interferon free regimens on clinical and cost outcomes for chronic hepatitis C genotype 1 patients," Journal of Hepatology, vol. 60, no. 3, pp. 530-537, 2014.

[23] R. Fox, "Going viral: why eliminating the burden of hepatitis C requires enhanced cooperation between specialists and primary care providers," Digestive Diseases and Sciences, vol. 61, no. 12, pp. 3381-3383, 2016.

[24] A. Do, Y. Mittal, A. Liapakis et al., "Drug authorization for sofosbuvir/ledipasvir (Harvoni) for chronic hcv infection in a real-world cohort: a new barrier in the HCV care cascade," PLoS One, vol. 10, no. 8, article e0135645, 2015.

[25] S. Barua, R. Greenwald, J. Grebely, G. J. Dore, T. Swan, and L. E. Taylor, "Restrictions for Medicaid reimbursement of sofosbuvir for the treatment of hepatitis $\mathrm{C}$ virus infection in the United States," Annals of Internal Medicine, vol. 163, no. 3, pp. 215-223, 2015.

[26] F. Nwulia O, M. A. Mahmoud A, I. R et al., "Primary care providers knowledge, attitude and practices related to hepatitis $\mathrm{C}$ screening and treatment in the oral direct acting antiviral agents era," Journal of Community Medicine \& Health Education, vol. 6, no. 5, 2016.

[27] S. Kattakuzhy, C. Gross, B. Emmanuel et al., "Expansion of treatment for hepatitis $\mathrm{C}$ virus infection by task shifting to community-based nonspecialist providers: a nonrandomized clinical trial," Annals of Internal Medicine, vol. 167, no. 5, pp. 311-318, 2017.

[28] T. G. McGinn, D. Gardenier, L. K. McGinn et al., "Treating chronic hepatitis $\mathrm{C}$ in the primary care setting," Seminars in Liver Disease, vol. 25, no. 1, pp. 65-71, 2005.

[29] P. Sebhatu and M. T. Martin, "Genotype 1 hepatitis $C$ virus and the pharmacist's role in treatment," American Journal of Health-System Pharmacy, vol. 73, no. 11, pp. 764-774, 2016.

[30] S. Yang, R. B. Britt, M. G. Hashem, and J. N. Brown, "Outcomes of pharmacy-led hepatitis C direct-acting antiviral utilization management at a Veterans Affairs Medical Center," Journal of Managed Care \& Specialty Pharmacy, vol. 23, no. 3, pp. 364-369, 2017. 


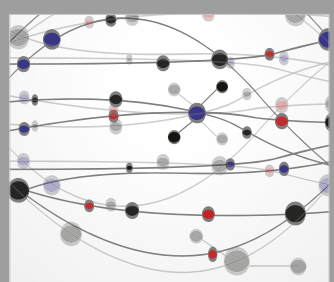

The Scientific World Journal
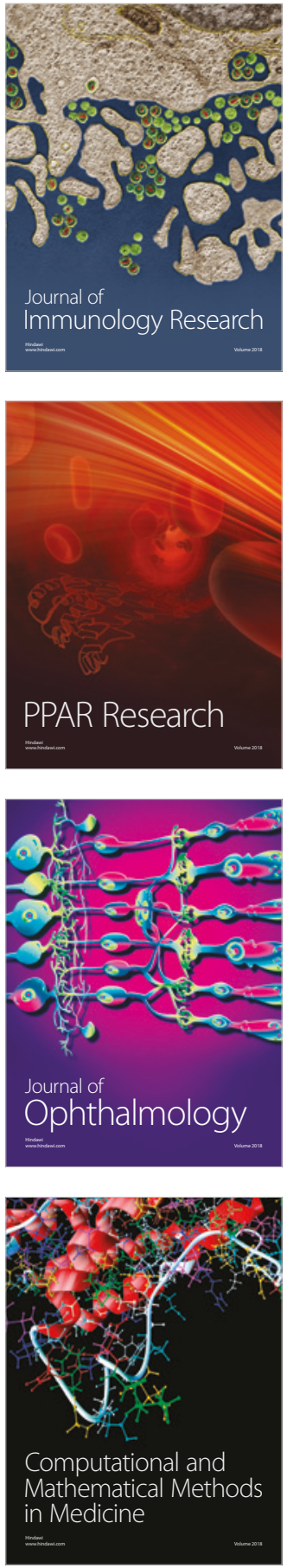

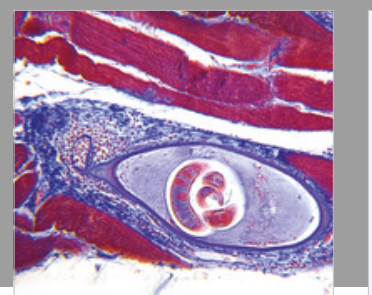

Gastroenterology Research and Practice

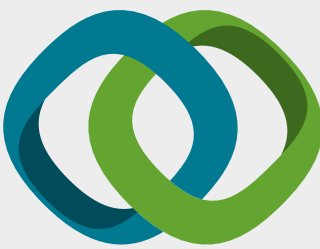

\section{Hindawi}

Submit your manuscripts at

www.hindawi.com
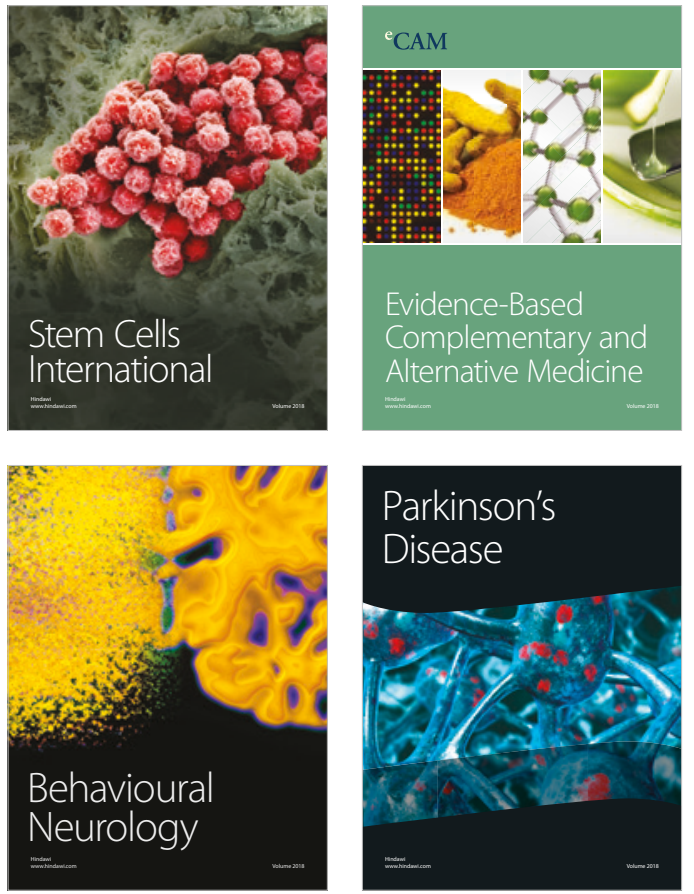

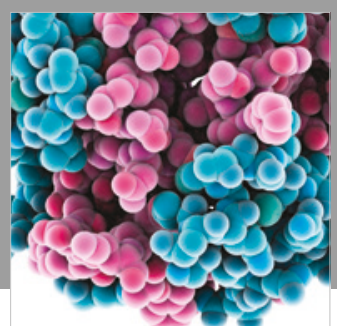

ournal of

Diabetes Research

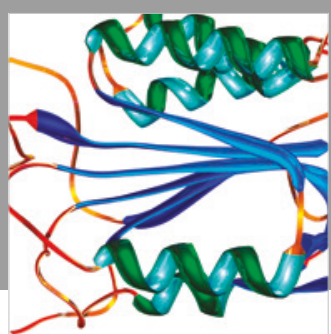

Disease Markers
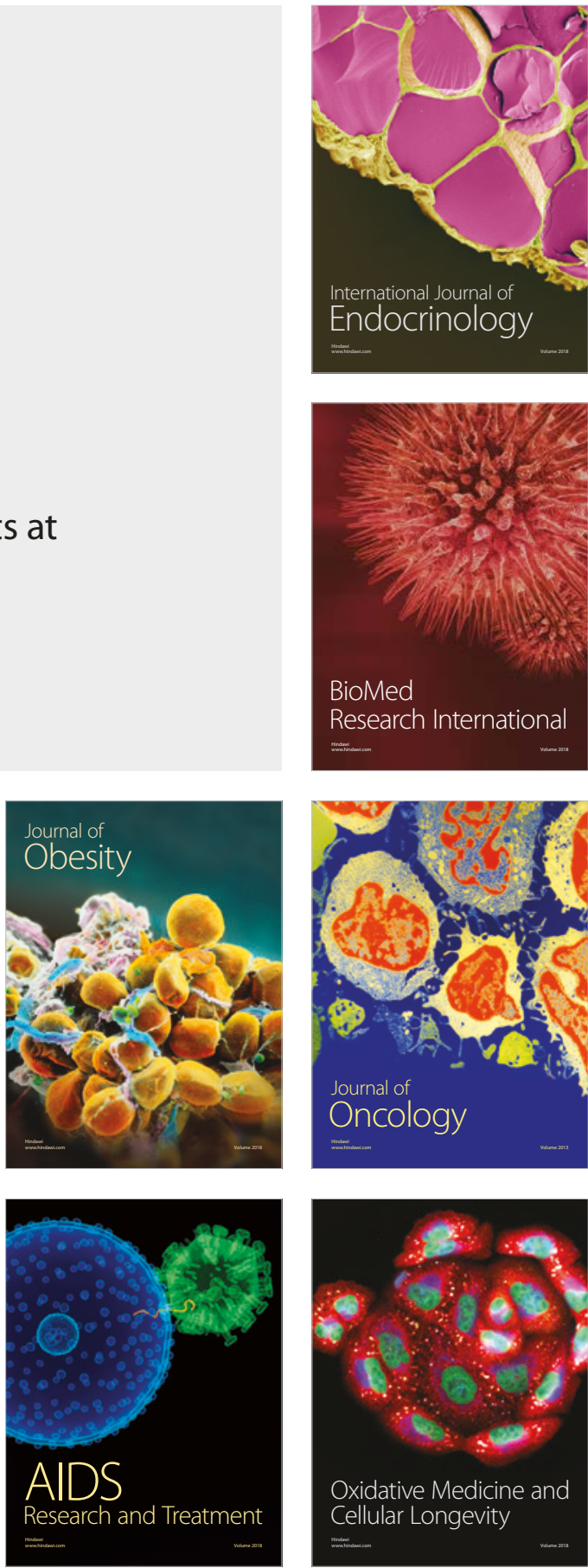